\title{
ATIVIDADE PESQUEIRA NO RIO POTY, MUNICÍPIO DE CASTELO DO PIAUÍ, PIAUÍ, BRASIL: CONHECIMENTO E USO DA FLORA
}

\author{
FISHING ACTIVITY IN THE POTI RIVER, CASTELO DO PIAUÍ CITY, PIAUÍ, BRAZIL: \\ KNOWLEDGE AND USE OF THE FLORA
}

Joanice Costa AMORIM ${ }^{1 *}$; Karina Neoob Carvalho CASTRO²; Romildo Ribeiro SOARES ${ }^{3}$; Roseli Farias Melo de BARROS $^{4}$; Ivanilza Moreira de ANDRADE ${ }^{5}$

${ }^{1}$ E. E. Gervásio dos Santos Costa, Rua Minas Gerais, 974, Centro, CEP: 78875-000, Gaúcha do Norte - Mato Grosso, Brasil. ${ }^{2}$ Embrapa Meio-Norte, Av. Duque de Caxias, 5.650, Buenos Aires, CEP: 64006220, Parnaíba - Piauí, Brasil; ${ }^{3,4}$ Departamento de Biologia; Universidade Federal do Piauí, Av. Universitária, s/n, Bairro Ininga, CEP 64049-550, Teresina - Piauí, Brasil.; ${ }^{5}$ Programa de Pós-Graduação em Desenvolvimento e Meio-Ambiente (MDMA/UFPI), Núcleo de Referências em Ciências Ambientais do Trópico Ecotonal do Nordeste (TROPEN), Av. Universitária, 1310, CEP 64049-550, Teresina - Piauí, Brasil.;*contato: e-mail: joanicee_amorim@hotmail.com

\section{RESUMO}

Estudos sobre uso sustentável de recursos naturais a partir da valorização e aproveitamento de experiências adquiridas pelas comunidades são importantes para a definição de sistemas de manejo e incentivo ao conhecimento científico e tecnológico dessas comunidades. Objetivou-se levantar a compreensão que os pescadores artesanais da colônia Z-9, município de Castelo do Piaú, e seus familiares, possuem sobre o uso de plantas na pesca. Os dados foram coletados a partir de formulários semiestruturados. Os métodos quantitativos utilizados foram Valor de Uso (VU), índices de ShannonWiener (H'), Simpson (D) e rarefação. Registraram-se 64 espécies, pertencentes a 54 gêneros e 30 famílias, sendo 56 espécies utilizadas pelos próprios peixes (42 como alimentícias, nove como berçário, oito como abrigo para desova e cinco como refúgio). Os resultados apontam a importância do uso de espécies vegetais na atividade pesqueira e na obtenção das informações para a conservação da biodiversidade da flora na região.

Palavras-chave: Atividade pesqueira, conhecimento tradicional, diversidade vegetal, etnobotânica, uso de plantas

\section{ABSTRACT}

Studies on sustainable use of natural resources based on the valorization and application of the experiences acquired by traditional communities are essential for defining management systems and incentive to furthering scientific and technological knowledge of these communities. The objective was to study the knowledge that the artisan fishermen of the Z-9 colony, in the municipality of Castelo do Piauí, Piauí State, and their relatives, possess about of use plants in fishing. Data were collected using semi-structured questionnaires. The quantitative methods used were General Use Value (VU), ShannonWiener indexes (H'), Simpson (D) and rarefaction. Sixty-four species belonging to 54 genera and 30 families were recorded, being 56 species used by the fish themselves ( 42 as food, nine as nurseries, eight as shelters for spawning and five as refuges). The results indicate the importance of the use of plant species in fishing and for obtaining information for the conservation of the region's plant biodiversity.

Keywords: Fishing activity, traditional knowledge, plant diversity, ethnobotany, plant use

\section{INTRODUÇÃO}

As comunidades tradicionais são compostas de pessoas com culturas diferentes, modo próprio de organização social e que fazem uso dos recursos naturais a partir da utilização de conhecimentos, inovações e práticas adquiridas pela tradição como condição para sua formação cultural, social, religiosa, ancestral e econômica (MEDEIROS e ALBUQUERQUE, 2012). Desta forma, as comunidades podem ser classificadas em caiçaras, quilombolas, indígenas, pescadores artesanais, dentre outras (DIEGUES e ARRUDA, 2000).

O conhecimento das comunidades tradicionais sobre o uso de plantas é muito amplo e, muitas vezes, apresenta-se como um dos recursos disponíveis em que as populações rurais dos países em desenvolvimento possuem (PASA et al., 2005). O estudo desta interação entre homem e planta contribui para o aperfeiçoamento e compreensão da relação do ser humano com o ambiente (ALBUQUERQUE, 2005). Esta interação é estudada pela Etnobotânica (VÁSQUEZ et al.,2014). 
Estudos relacionados à Etnobotânica informam a sociedade em geral e a comunidade científica sobre o uso das plantas pelas comunidades tradicionais rurais e urbanas (CARNEIRO et al., 2010). Neste contexto, pode-se ressaltar que a Etnobotânica está presente na vida dos pescadores (BEGOSSI, 2004) devido ao contato direto que estes mantêm com o meio ambiente, designando um elo ocupacional (DIEGUES e ARRUDA, 2000). Esse elo se estende a processos relacionados ao ecossistema, como o uso de espécies vegetais nas relações tróficas (BEGOSSI, 2004).

Os estudos etnobotânicos mostram a evolução de espécies individuais e o comportamento das populações, as intervenções das pessoas no meio ambiente, bem como a biologia de plantas de interesse, promovendo a sustentabilidade e o manejo adequado do ambiente (ALBUQUERQUE e ANDRADE, 2002). Dessa forma, a Etnobotânica contribui com o resgate do conhecimento tradicional, evitando a perda dos saberes tradicionais em um cenário de mudanças socioeconômicas (GANDOLFO e HANAZAKI, 2011).

Dentre os trabalhos etnobotânicos realizados com pescadores artesanais no Brasil, citam-se: Nascimento (2014), em comunidades pesqueiras de Parnaíba e Cajueiro da Praia, Piauí; Santos et al. (2015), município de União, Piauí; Roque (2017), litoral central de Santa Catarina; Santos (2017), rio Parnaíba, Miguel Alves, Piauí; Silva (2018), realizado com pescadores artesanais do município de Amarante, Piaú. Porém, poucos estudos têm sido realizados sobre o conhecimento dos pescadores acerca do uso de plantas pela fauna ictiológica na região do município de Castelo do Piauí, nordeste brasileiro.

O município de Castelo do Piauí, Estado do Piauí, é drenado pelos rios Poti e Cais, pelos riachos Sambaíba, São Francisco e São Miguel, e apresenta a pesca artesanal como uma das atividades realizadas pelos seus habitantes (SANTOS e AQUINO, 2015). A área proposta está na categoria de prioridade extremamente alta para a conservação da biodiversidade, segundo Projeto de Conservação e Utilização Sustentável da Diversidade Biológica Brasileira (PROBIO) (BRASIL, 2007). Há uma diversidade de espécies de plantas de fácil acesso à comunidade e uma área que a população utiliza para lazer, como, por exemplo, o Cânion do rio Poti.

$\mathrm{O}$ estudo foi realizado devido aos poucos trabalhos com pescadores nesta região, por possuir uma quantidade de espécies vegetais que são úteis na atividade pesqueira e uma necessidade de conhecer a diversidade vegetal local. Deste modo, os resultados obtidos poderão fornecer subsídios para a conservação das espécies locais por meio do manejo e uso sustentável, além de servir de base para novos estudos na região.

\section{MATERIAL E MÉTODOS \\ Área de estudo}

A região estudada está localizada no nordeste brasileiro, município de Castelo do Piauí, Estado do Piauí, Brasil. Possui uma área de $2.378,847 \mathrm{~km}^{2}$, situado a $239 \mathrm{~m}$ de altitude (latitude: 5¹9'20”S e longitude: 41 33 '09'W na sede municipal) e população estimada para 2018 de 19.715 habitantes (IBGE, 2017). A densidade demográfica é de $9,01 \mathrm{hab} / \mathrm{km}^{2}$, com 6.859 habitantes vivendo na zona rural (IBGE, 2017) (Figura 1). O clima desta região varia de subúmido úmido a subúmido seco (THORNTHWAITE e MATHER, 1955), no qual o período seco é de aproximadamente sete meses (meados de junho a meados de dezembro). A temperatura mínima é de $23^{\circ} \mathrm{C}$ e a máxima de $35^{\circ} \mathrm{C}$, com precipitação pluviométrica de 1.042,3 mm (IBGE, 2017).

A vegetação é composta por Cerradão (4\%), Campo Cerrado (7\%), Complexo Campo Maior (carrasco) $(82,7 \%)$ e Caatinga Arbustiva (6,3\%) (BRASIL, 1973; SANTOS e AQUINO, 2015). O Cerradão é caracterizado por árvores com porte de $5 \mathrm{~m}$ de altura, cujas copas não se tocam, estrato arbustivo sem nitidez, gramíneas ralas, palmeiras anãs e plantas lenhosas rasteiras (SANTOS e AQUINO, 2015). O Campo Cerrado apresenta árvores esparsas, entre 2 e $5 \mathrm{~m}$, com galhos e troncos retorcidos, gramíneas, plantas baixas e plantas lenhosas rasteiras (SANTOS e AQUINO, 2015). A vegetação do Complexo Campo Maior prevalece na área de estudo, com características rupestres, baixa altitude e com o domínio de vegetação de ecótonos entre cerrado/caatinga, cerrado/mata com vegetação caducifólia e subcaducifólia estacionais, predomínio da vegetação herbáceo-subarbustivo sobre o arbustivo-arbóreo e presença de carnaubais em planícies inundáveis (SANTOS e AQUINO, 2015). A classe Caatinga corresponde a 6,3\% da área em estudo e apresenta-se sob a forma arbustiva, com estrato arbustivo uniforme e árvores espinhosas mais ou menos homogêneas (SANTOS e AQUINO, 2015). 


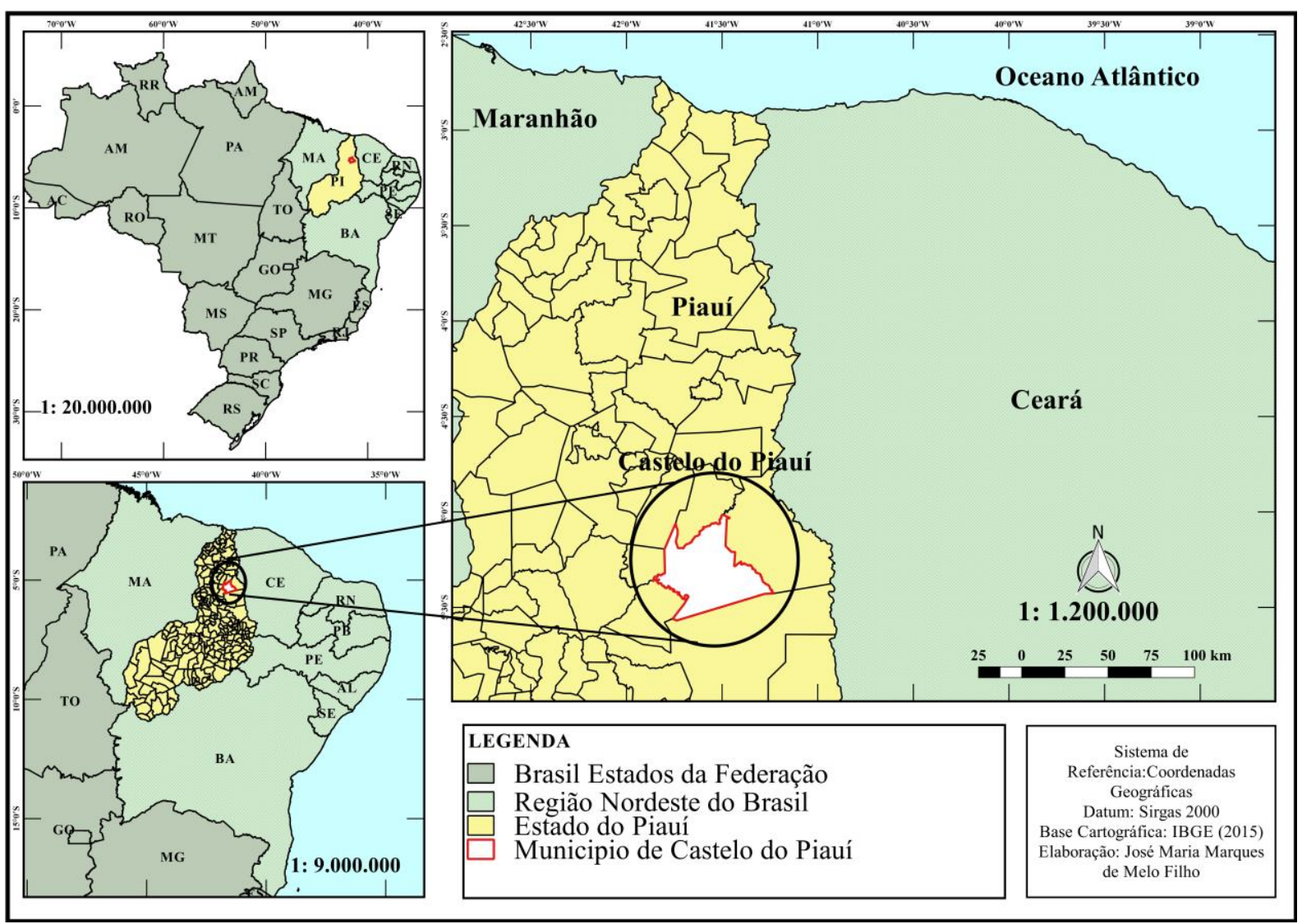

Figura 1. Localização do município de Castelo do Piauí, Piauí, nordeste do Brasil. Fonte: Elaborado: José Maria Marques de Melo Filho, 2019.

\section{Coleta de dados}

Esta pesquisa foi aprovada e consubstanciada pelo Comitê de Ética em Pesquisa (CEP) da Universidade Federal do Piauí - UFPI (nº 2.049.486) e cadastrada no Sistema Nacional de Gestão do Patrimônio Genético e do Conhecimento Tradicional Associado (SISGEN) sob no A34B560.

A pesquisa seguiu a metodologia proposta por Begossi et al. (2009), na qual, em comunidades com até 50 famílias, devem ser feitas entrevistas em todas as residências. Para possibilitar a familiarização e a confiança dos pescadores, foi utilizado o método de Rapport (BARBOSA, 2007). Inicialmente, o projeto foi apresentado ao presidente da Colônia de Pescadores para a obtenção de informações sobre o número de pescadores e seus endereços. Quando consentida a participação na pesquisa, foi solicitado que os entrevistados assinassem o Termo de Consentimento Livre e Esclarecido, segundo as exigências éticas do Conselho Nacional de Saúde (RESOLUÇÃO 466/12). Este termo é assinado pelos participantes antes das entrevistas, dando permissão para que as mesmas sejam realizadas e que estão cientes da condução do estudo.

A pesquisa foi realizada entre outubro de 2016 a outubro de 2017, usando observação participativa e entrevistas com aplicação de formulários padronizados semiestruturados (APOLINÁRIO, 2006). As informações foram registradas com auxílio de instrumentos como câmera fotográfica, diário de campo e gravador (SILVA, 2000).

Para a coleta de espécies de plantas, foi realizada a técnica de turnê-guiada (BERNARD, 1988), visitando os locais de pesca juntamente com os informantes. A coleta e herborização seguiram a metodologia padrão para plantas vasculares (MORI et al., 1989). As plantas foram identificadas no Herbário Graziela Barroso (TEPB) da UFPI e a confirmação dos nomes válidos, fotografia das espécies e abreviaturas dos nomes dos autores estão de acordo com os sites W3Tropicos (2017) e The PlantListData Base (http://www.theplantlist.org/).

As exsicatas foram depositadas no TEPB, com duplicatas remetidas para o Herbário HDELTA, Campus de Parnaíba, ambos da Universidade Federal do Piauí. Utilizou-se auxílio de especialistas para identificação ou confirmação das identificações dos espécimes. A lista das espécies citadas foi organizada pelo APG IV (2016). A origem (nativas ou exóticas) foi procedida de acordo com suas 
origens biogeográficas, utilizando o publicado na Lista de Espécies da Flora do Brasil 2020, em construção (2018).

As espécies estudadas foram categorizadas de acordo com seus usos: construção de embarcações (a parte do caule é usada para construir canoas ou barcos), apetrechos de pesca (confecção da vara de anzol e groseira, por exemplo), alimentícia (espécies que os peixes se alimentam), berçário (plantas aquáticas ou submersas nas margens do rio onde os alevinos vivem), abrigo para desova (plantas onde os peixes deixam seus ovos), refúgio (plantas utilizadas pelos peixes para se esconderem ou protegerem de predadores), ictiotóxicas (espécies que são tóxicas para os peixes), atrativas (plantas usadas para atrair os peixes durante a captura) e daninhas (espécies que causam algum dano na atividade pesqueira).

\section{Análise dos dados}

Para o uso das espécies citadas pelos pescadores, utilizou-se o cálculo de Valor de Uso (VU), conforme Lucena et al. (2012), que sugeriram modificação na fórmula proposta por Rossato et al. (1999), ou seja, VU $=(\Sigma U) / n$, onde o valor de uso de uma espécie (VU) é dado como o somatório do número de usos mencionados pelo informante $(\mathrm{U})$, dividido pelo número total de informantes $(\mathrm{n})$. A partir de então, a utilização das espécies foi classificada como de uso atual ( $\mathrm{VU}_{\mathrm{a}}$, para as espécies usadas com frequência; uso potencial $\left(\mathrm{VU}_{\mathrm{p}}\right)$ para as espécies em que raramente ou nunca o uso é feito; e uso geral $\left(\mathrm{VU}_{\mathrm{g}}\right)$, que é o somatório dos valores de uso atual e potencial.

Para analisar o conhecimento etnobotânico por gênero e faixa etária, foi comparado o número de indicações e a riqueza de espécies. Para o cálculo do Índice de Diversidade de Shannon-Wiener, seguiu-se a metodologia proposta por Magurran (1988), calculado pela fórmula $H^{\prime}=\sum\left(P_{i}\right)\left(\log _{2} P_{i}\right)$, onde $H^{\prime}=$ índice de diversidade de Shannon-Wiener; $S=$ número de espécies; $P_{i}=$ proporção relativa de abundância da espécie $i$.

Para a análise de diversidade e conhecimento de espécies de plantas por gênero e faixa etária, utilizou-se o cálculo do Índice de Simpson (KREBS, 1989; MAGURRAN, 1988). Este é um índice de dominância e reflete a probabilidade de dois indivíduos escolhidos ao acaso pertencerem à mesma espécie, o qual varia de 0 a 1 e quanto mais alto for, maior a probabilidade de os indivíduos pertencerem à mesma espécie, ou seja, maior a dominância e menor a diversidade, calculado pela equação: $1-D=$ $1-\sum(P i)^{2}$, onde $\mathrm{D}=$ Índice de Diversidade de Simpson; $P i=$ proporção de indivíduos na $i$-ésima espécie.

Devido aos tamanhos amostrais serem distintos e as variáveis medidas serem sensíveis a este fator, utilizou-se o Método de Rarefação, que calcula o número esperado de espécies em cada amostra para um tamanho de amostra padrão. Para o cálculo de rarefação foi utilizado o programa Ecosim (GOTELLI e ENTSMINGER, 2001). Este deve ser usado somente para amostras padronizadas, em habitats iguais ou similares. Tem-se como ressalva que as curvas não podem ser extrapoladas para além do número de indivíduos na amostra maior $(\mathrm{N})$.

Para o cálculo da rarefação com o número esperado de espécies foi usada a seguinte equação: $E(S)=\sum\left[1-\left(N-N_{i} / n\right) /(N / n)\right]$, onde $E(S)=$ número esperado de espécies em uma amostragem aleatória (riqueza esperada para n); $S=$ número total de espécies registradas; $N=$ número total de indivíduos; $N i$ = número de indivíduos da espécie $i$ (i-ésima espécie); e $n=$ tamanho padronizado da amostra. Obs.: $(N / n)=N ! / n !(N-n) !$

Para a obtenção de estimativas de riqueza de espécies foram utilizados dois estimadores para a curva de acumulação, os quais usam dados de incidência de espécies nas amostras estudadas. Os estimadores de riqueza foram Chao 2 e Jackknife 2 (COLWELL e CODDIGTON, 1994; COLWELL, 2004) para comparar o número estimado de espécies a partir dos dados amostrais. Chao 2 é calculado pela equação: $S_{c}=s+Q_{\mathrm{j}}^{2} / 2 Q_{2}$ e Jackknife 2, pela equação: $\hat{S}=s+[n-1 / n]^{k}$

\section{RESULTADOS}

Foram realizadas 55 entrevistas com homens (29) e mulheres (26), que representaram todos os pescadores artesanais cadastrados, juntamente com suas esposas e filhos. A idade variou entre 18 a 71 anos, com idade média de 44,9 anos. A classificação para faixa etária seguiu a do IBGE (2010): jovens 9,1\% (18 a 24 anos); adultos 78,9\% (25 a 59 anos) e idosos 10,9\% (a partir de 60). Abordou-se sobre o conhecimento do uso das plantas pelos pescadores e uso dos peixes, direta ou indiretamente.

Os pescadores mencionaram 64 espécies vegetais, distribuídas em 54 gêneros e 30 famílias, das quais Fabaceae (12) e Poaceae (sete) apresentaram maior número de espécies (Anexo 1). Os gêneros com maior número de espécies foram Aspidosperma Mart. \& Zucc. (três), seguido de Anadenanthera 
Speg., Combretum Loefl., Handroanthus Mattos, Hymenaea L. e Mimosa L. (todos com duas espécies cada).

Quanto à distribuição geográfica, a maioria das espécies é nativa $(91,5 \%)$ e as espécies exóticas estão distribuídas em três famílias, seis gêneros e seis espécies: Petiveria alliacea L. (tipi), Bambusa sp. (bambu), Urochloa mutica (Forssk.) T.Q.Nguyen (capim), Oryza sativa L. (arroz), Malpighia glabra L. (acerola) e Zea mays L. (milho) (Anexo 1).

O habitat da maioria das espécies é terrestre $(92,0 \%)$, enquanto as demais são macrófitas aquáticas, todas nativas: Echinodorus lanceolatus Rataj. (fixa); Nymphaea rudgeana G.Mey. (flutuante enraizada, fixa), Salvinia auriculata Aubl. (flutuante); Ludwigia helminthorrhiza (Mart.) H.Hara (flutuante livre ou fixa) e Ceratophyllum demersum L. (fixa).

O hábito de vida dominante foi o arbóreo $(49,3 \%)$, seguido de arbustivo $(22,2 \%)$, herbáceo $(15,9 \%)$, lianescente $(9,4 \%)$ e subarbustivo $(3,2 \%)$ (Anexo1).

Os habitats das plantas referidos pelos entrevistados foram o terrestre e o aquático. As espécies encontradas na água foram identificadas como aquáticas flutuantes ou enraizadas, e com folhas flutuantes ou submersas (ANDRADE et al., 2014), as quais são utilizadas como berçário para alevinos, local de desova e esconderijo, protegendo-os de predadores. Dentre as espécies usadas como berçário para os peixes (proteção para os alevinos), cita-se Combretum leprosum (mufumbo), que embora possua importância para os peixes, prejudica a pesca, pois o artefato usado se prende ao corpo da planta (Anexo $1)$.

Quanto ao local de coleta das espécies de plantas utilizado pelos pescadores, a mata foi a mais citada $(84,3 \%)$, seguida pela margem do rio $(12,1 \%)$ e pela água do rio $(3,6 \%)$. O fato de a mata ser o local mais citado se deve à facilidade em encontrar espécies em abundância, próximo ao local de moradia, não havendo necessidade de as pessoas se deslocarem por percursos mais longos.

Quanto às partes das plantas utilizadas, o fruto foi o mais citado $(30,7 \%)$, seguido do caule $(23,8 \%)$, flor $(19,8 \%)$, folhas $(12,9 \%)$, sementes/raiz $(5,0 \%)$ e ramos $(3,0 \%)$. Os frutos foram os mais citados devido à apreciação como alimento, principalmente nas espécies ripícolas. As flores e sementes, segundo os pescadores, também servem de alimento para os peixes ao caírem na água. $\mathrm{O}$ caule é utilizado para a construção de canoas; para a confecção dos artefatos de pesca, eles utilizam as madeiras mais consistentes e firmes; para a construção da vara de anzol são utilizadas os mais flexíveis e maleáveis.

Já os ramos são utilizados durante a pesca para prender os enganchos às margens do rio. No entanto, os ramos também podem prejudicar a pesca, como, por exemplo, rasgar os instrumentos de pesca que ficam presos. Quanto às folhas, seu uso é referido para refúgio e reprodução (desova) dos peixes. Enquanto que as raízes, utilizadas pelos pescadores, são maceradas para terem um maior aproveitamento das substâncias, pois as espécies selecionadas são tóxicas para os peixes e podem levar à extinção das espécies se usadas de forma incorreta. Elas são jogadas na água para asfixiar, paralisar ou envenenar os peixes, facilitando a sua captura.

As espécies referidas pelos pescadores enquadram-se nas categorias alimentícias, construção de embarcações, confecção de apetrechos de pesca, abrigo para desova, berçário para os alevinos, refúgio, atrativas, daninhas e as que são consideradas ictiotóxicas. A maioria das espécies citadas é de uso alimentício (42), das quais 37 se distribuem ao longo da margem do rio e cujos frutos caem na água servindo de alimento para os peixes. Destas, cinco foram referidas para alimentar os peixes, tais como Anacardium occidentale, Manihot esculenta, Malpighia glabra, Oryza sativa e Zea mays. Dentre estas, três (O. sativa, M. glabra e M. esculenta) são utilizadas pelos pescadores para atrair os peixes e capturálos.

Para a confecção de apetrechos de pesca foram citadas 13 espécies e oito para construção e conserto de embarcações. As espécies em comum utilizadas para estes dois fins foram Handroanthus serratifolius e Handroanthus impetiginosus. Apenas o pequizeiro-do-pará e sapucaia, utilizadas na construção de embarcações, não foram coletados, pois são compradas em madeireiras oriundas do Pará e Maranhão, respectivamente. Segundo os pescadores, o uso destas espécies está relacionado às propriedades da madeira, como durabilidade, qualidade e resistência.

Algumas folhas submersas ou da lâmina d'água de espécimes das macrófitas, distribuídas ao longo da margem do rio, servem como berçário para os alevinos $(14,0 \%)$, abrigo para desova $(12,5 \%)$ e refúgio pelos peixes $(7,8 \%$ ) (Anexo 1). Além das espécies citadas como benéficas aos peixes, 15,6\% são prejudiciais, de alguma forma, a sua sobrevivência ou comprometendo a pesca (daninhas) e 9,4\% podem causar toxicidade nos peixes. 
Dentre as que comprometem a pesca, devido a seus ramos se engancharem no artefato de pesca, citam-se: Echinodorus lanceolatus (capim-beira-d'água), Nymphaea rudgeana (aguapé), Cyperus digitatus (capim-tiririca), Hymenachne amplexicaulis (capim), Ludwigia helminthorrhiza (aguapé), Megathyrsus maximus (capim), Salvinia auriculata (igarapé-novo), dentre outras. As referidas como ictiotóxicas (causam a morte ou imobilização dos peixes) foram Petiveria alliacea (tipi), Copernicia prunifera (carnaúba), Magonia pubescens (tingui), Ipomoea asarifolia (salsa), Curatella americana (sambaíba) e Simarouba versicolor (praíba).

Podemos destacar as raízes da espécie Petiveria alliacea, que eram utilizadas para extrair, através do processo de maceração, substâncias para envenenar ou embebedar os peixes. Este método de captura era usado pelos antepassados, pois facilitava a pesca. Os pescadores entrevistados não utilizam mais esta técnica, pois acreditam que pode envenenar ou intoxicar tanto os peixes adultos quanto os alevinos, o que poderia acarretar na diminuição do número de indivíduos e risco de extinção da espécie.

Outros táxons citados como ictiotóxicos foram Copernicia prunifera e Magonia pubescens, também utilizados para captura de peixes por seus antepassados. Magonia pubescens possui uma toxina que impede a respiração dos peixes, asfixiando-os. As folhas de carnaúba eram utilizadas em associação com o tingui (o tingui era enrolado nas folhas da carnaúba) e juntas facilitavam a dispersão da substância pela água, isso também ajudava no seu manuseio.

Ipomoea asarifolia (salsa), de acordo com os entrevistados, prejudica e causa a morte dos peixes se estes se alimentarem de alguma parte desta planta. Cascas trituradas ou raspas do caule de Curatella americana (sambaíba) e Simarouba versicolor (praíba) também foram citadas como métodos de captura devido as suas toxinas, pois "atordoam" os peixes, levando-os à superfície da água, facilitando sua coleta. O conhecimento sobre a toxicidade destas espécies foi adquirido com os pescadores mais velhos, por meio da observação direta, quando ainda eram crianças, vendo/ajudando seus pais a realizarem esta atividade na pesca.

Quanto ao índice de Valor de Uso, as espécies mais representativas foram Hymenachne amplexicaulis (capim 1), Megathyrsus maximus (capim 2) e Urochloa mutica (capim 3), todas com mesmo valor de uso $\left(\mathrm{VU}_{\mathrm{g}}=2,00 ; \mathrm{VU}_{\mathrm{a}}=1,60 \mathrm{e} \mathrm{VU}_{\mathrm{p}}=0,40\right)$ e tendo mais de um uso pelos peixes. Outras espécies importantes na região que tiveram valores significativos foram Combretum laxum (jaramataia, $\mathrm{VU}_{\mathrm{a}}=0,291$ ); Andira retusa (angelim, $\mathrm{VU}_{\mathrm{a}}=0,236$ ) e Copernicia prunifera (carnaúba, $\mathrm{VU}_{\mathrm{a}}=0,145$ ) (Anexo 1).

Com relação à diversidade do conhecimento por gênero, as mulheres $(n=26 ; 47,3 \%)$ citaram 35 espécies em 87 citações, apresentando Índice de Shannon-Wiener $\left(\mathrm{H}^{\prime}=3,329\right)$. Os homens, por sua vez, mostraram ter um conhecimento maior que as mulheres $(n=29 ; 52,7 \%)$, citaram 55 espécies de 243 citações com H' $=3,532$. O valor do índice de Simpson para o gênero foi de $1-\mathrm{D}=0,9565$ para o feminino e $1-\mathrm{D}=0,9612$ para o masculino.

Com relação à diversidade de conhecimento de espécies de plantas úteis por faixa etária, foi observado que os jovens $(\mathrm{n}=5 ; 9,1 \%)$ citaram apenas 10 espécies com total de 13 citações; os adultos $(\mathrm{n}=44,80,0 \%)$ citaram 52 espécies de 259 citações, enquanto que os idosos $(\mathrm{n}=6,10,9 \%)$ citaram 36 espécies de 61 citações. O índice de Shannon foi de H' = 2,205 para jovens (18-24 anos), H' = 3,493 para adultos (25-59 anos) e H'=3,402 para idosos (60 anos ou mais). O valor do índice de Simpson por faixa etária para jovens foi de $1-\mathrm{D}=0,8757$, para adultos $1-\mathrm{D}=0,9605$ e idosos $1-\mathrm{D}=0,9600$. Os jovens conhecem quantidade menor de espécies do que os adultos e idosos. A espécie mais citada pelos jovens foi o bambu, com três citações.

A curva de rarefação, calculada para gênero e faixa etária, e o número esperado de espécies pelo total de indivíduos na amostra citada a partir dos entrevistados, evidenciam que a riqueza de espécies conhecidas não atingiu a assíntota (estabilização). Considrando que o número de entrevistados foi o total da população (55), podemos inferir que do total de espécies conhecidas pela amostra estudada, no geral, a maioria das pessoas conhece poucas espécies.

A curva de acumulação para todas as espécies observadas (obs.) demonstra o início de uma assíntota. No entanto, as curvas para Chao $2\left(S_{c}=110,7\right)$ e Jackknife $2\left(S_{j}=93,96\right)$ não se estabilizaram, continuam a crescer, demonstrando que necessitar-se-iam de mais amostras para atingir a assíntota (Figura 2). 


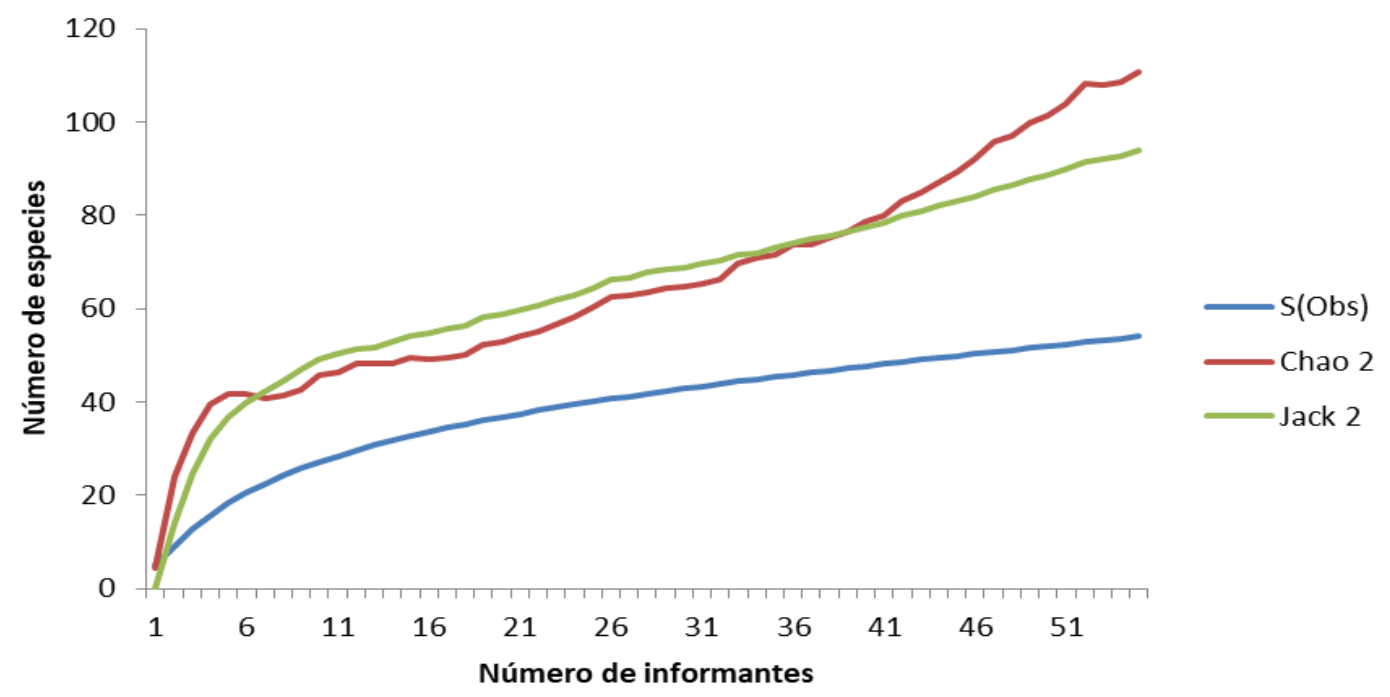

Figura 2. Curva de acumulação das espécies citadas pelo número de informantes do município de Castelo do Piauí, Piauí. Legenda: S(Obs) espécies observadas; Chao 2 estimador de riqueza baseado na incidência de espécies (ou presença/ausência dos dados que quantifiquem raridade- ou o número de uniques/duplicates - ou o número de espécies encontradas em somente 1 ou 2 amostras, respectivamente) e Jackknife 2 estimador de riqueza baseado na abundância (abundância aqui quantifica raridade - ou o número de singletons/doubletons - ou o número de espécies representadas por somente 1 ou 2 indivíduos, respectivamente).

\section{DISCUSSÃO}

Considerando a origem das espécies na área estudada, a riqueza e uso das nativas foram maiores, mostrando que os pescadores artesanais estudados têm maior contato com essas plantas e as utilizam para suas atividades. Resultado semelhante foi encontrado no trabalho de Lopes e Lobão (2013), em Itaúnas, Conceição da Barra, Espírito Santo, em que foram citadas $81,0 \%$ das espécies como de origem nativa. Sousa et al. (2012) também registraram número de espécies nativas (62\%) em Barra Grande e Morro da Mariana no Delta do Parnaíba, Piauí, sendo significativo.

Segundo Baptista et al. (2013), a riqueza de espécies nativas e exóticas revela o dinamismo do conhecimento botânico local e a habilidade de se ajustar as necessidades da população local. O uso de espécies nativas está ficando cada vez mais difícil e um dos motivos seria a diminuição das matas nativas, de onde se retira a matéria-prima (ANDRADE et al., 2016). Neste sentido, percebe-se que a conservação dos recursos biológicos tem forte ligação com o conhecimento das comunidades tradicionais (RIBEIRO e BRITO, 2018). Dessa maneira, a exploração dos recursos naturais é desenvolvida pelos povos tradicionais, os quais mantêm papel relevante na natureza, pois protegem e fazem o manejo destes ambientes para usufruir destes produtos como meio de subsistência (PASA et al., 2005).

As espécies nativas são utilizadas tanto pelo homem para a construção de canoas e confecção de apetrechos de pesca, como também pela ictiofauna da região de Castelo do Piauí. Segundo Roque (2017), as espécies nativas do litoral central de Santa Catarina são utilizadas principalmente para a construção de cascos de canoas, enquanto as exóticas são utilizadas em outras partes dos barcos e para a manutenção das embarcações. O hábito arbóreo apresentou o maior número de citações devido ao uso de espécies frutíferas para alimentação dos peixes e construção de embarcações. Resultado semelhante foi registrado por Lopes e Lobão (2013) e Wiryono (2017) com 50,6\% e 65,0\% das citações, respectivamente.

Vale ressaltar que as macrófitas aquáticas foram referidas por Macedo et al. (2012) como sendo importante habitat não somente para os peixes como para os invertebrados e aves aquáticas. São plantas bioindicadoras de atividade química ou de decomposição de um sistema natural, sendo capazes de caracterizar as propriedades físicas e químicas do ambiente natural (HEGEL e MELO, 2016), podendo indicar uma avaliação segura e confiável da qualidade do ambiente. Dentre as macrófitas registradas na atividade pesqueira, cita-se Salvinia auriculata, utilizada como bioindicadora de ambiente poluído, pois possui uma fácil propagação em corpos d'água novos e tem grande capacidade de absorver e concentrar poluentes metálicos sem apresentar intoxicação (SILVA, 2011).

A mata foi o local de ocorrência mais citado para as espécies vegetais. Segundo Melo e Deus (2008), no período seco (final de junho a início de dezembro) as plantas perdem suas folhas e apenas 
seus troncos permanecem na paisagem. Fonseca-Kruel e Peixoto (2004) também se referiram à mata como local mais citado para a coleta de espécies vegetais por pescadores, pois é neste ambiente que coletam as plantas para a construção de apetrechos, confecção de embarcações, dentre outras.

$\mathrm{O}$ caule se destaca como a parte da planta mais utilizada pelos pescadores na atividade pesqueira, por causa da confecção de apetrechos de pesca. Para Almeida e Jardim (2012) e Lopes e Lobão (2013), o caule também se destacou como a parte da planta mais utilizada, com 41,0\% e 33,0\% das citações, respectivamente. Este fato, também, foi observado no estudo de Begossi et al. (2004), que relataram que diversas plantas são conhecidas e utilizadas por diversos grupos de pescadores artesanais, pois mantêm relação direta com as atividades pesqueiras, destacando-se as relacionadas à fabricação de artefatos de pesca.

O bambu (Bambusa sp.) é utilizado como um dos recursos naturais em diversas áreas, servindo para confecção de artefatos de pesca, construção, recuperação de áreas degradadas, carvão vegetal, uso doméstico, geração de energia e carvão ativado (SANTOS et al., 2015; GENEROSO et al., 2016; BALDUÍNO JÚNIOR, 2016; SANTANA, 2017). O uso de plantas para a confecção de canoas foi uma importante prática no passado, em várias partes do Brasil (BAPTISTA et al., 2013). Hanazaki (2004) e Baptista et al. (2013) relataram o uso de timbaúva (Enterolobium contortisiliquum) e cedro (Cedrela fissilis) para a fabricação de canoas. Santos et al. (2015) citaram quatro espécies usadas na construção de canoas: pau-d'arco (Handroanthus spp.), cedro (Cedrela odorata), imbiratanha (Pseudobombax marginatum) e breu (Protium ssp.).

Andrade et al. (2016) levantaram as espécies arbóreas usadas para a construção de jangadas, chegando a um total de 13 espécies, dentre elas Anacardium occidentale e Caryocar brasiliense. Roque (2017) relatou o uso de 54 espécies utilizadas para construção, reparo e manutenção de canoas, sendo elas Hymenaea sp. (jatobá), Psidium cattleianum Sabine (araçá), Enterolobium sp. (timbuva) e Psidium guajava L. (goiabeira). Neste sentido, Nishida et al. (2008) citaram espécies em comum, como o paud'arco (Handroanthus spp.). Esta espécie e outras como o piqui (Caryocar coriaceum) e o pau-d'arco (Tabebuia spp.) também foram relatadas por Amorim (2010) como sendo utilizadas na construção e consertos de canoas. Portanto, é notável que o uso destas espécies seja fundamental para a continuidade desta prática, e mostra a importância de sua conservação.

As espécies de plantas citadas como alimentícias (frutos) para os peixes são encontradas próximas às margens do rio. Morais e Silva (2010) relataram sobre espécies de plantas utilizadas na alimentação dos peixes e que a conservação das áreas de ocorrência destas plantas é de suma importância para a manutenção dessas espécies, que é principal fonte de renda das comunidades ribeirinhas. Os frutos e as sementes das plantas tanto servem de alimento para os peixes como para a dispersão e indução de sementes por esses animais no ambiente em que vivem (MUNIZ et al., 2014; ALBUQUERQUE, 2015).

O fruto da carnaubeira é utilizado na alimentação de peixes, entretanto sua raiz é tóxica e dificulta a atividade de pesca. Para Gomes e Nascimento (2006), esta árvore possui várias utilidades, como, por exemplo, o uso das raízes para fins medicinais, enquanto o caule é usado para a construção civil e outras estruturas rudimentares; os frutos são alimento para os animais e as palhas são utilizadas para a confecção de artesanatos, adubo orgânico, produção de papel, dentre outras finalidades. Azevedo (2007) cita, em sua pesquisa, a confecção de um tipo de bota de carnaúba fabricada com a palha, que eram usadas por pescadores, pois os deixavam livres de esporadas de arraias. A confecção da bota era traçada de tal maneira que quando em contato com a água aumentava a sua resistência.

$\mathrm{Na}$ categoria ictiotóxica, está Ipomoea asarifolia (salsa), que pode ser encontrada nas margens do rio Poti com facilidade. No trabalho realizado por Pessoa et al. (2013), esta espécie é considerada tóxica para os ruminantes no Nordeste e na Ilha de Marajó. Também citada como ictiotóxica pelos pescadores está Petiveria alliacea (tipi). Camargo (2007) realizou um estudo etnofarmacobotânico, fitoquímico e farmacológico, no qual referiu seu uso na preparação de poção mágica usada para amansar os senhores de escravos. Esta observação levou os pesquisadores a analisar a atividade hipoglicemiante, a qual seria a responsável pelos transtornos mentais em consumidores (CAMARGO, 2007). Gomes (2006) avaliou os efeitos centrais e antinociceptivos das frações isoladas da raiz em camundongos e verificou uma diminuição significativa na atividade locomotora, rearing (comportamento exploratório vertical) e grooming (comportamento de autolimpeza) no teste de campo aberto, o que indicou uma possível ação depressora central.

Além disso, foi indicado aumento significativo do tempo de imobilidade nos camundongos quando aplicado o teste de nado forçado. Foi citada ainda nos trabalhos de Dominguez et al. (2002), Almeida (2011), Oliveira (2012) e Pantoja et al. (2013) como possuindo ação sobre o sistema nervoso 
central. Deste modo, observa-se que os efeitos causados por $P$. alliacea geram sonolência, insônia, alucinações, diminuição locomotora e imbecilidade, supondo serem estas as consequências geradas aos peixes durante a aplicação desse método pelos pescadores.

Para as espécies com maior Valor de Uso, destaca-se Copernicia prunifera. Esta espécie é abundante no município estudado, o que facilita seu uso. Nas comunidades estudadas por Sousa et al. (2012) em Barra Grande (VU = 2,64) e Morro da Mariana/PI (VU = 2,57), esta espécie também se destacou com maior valor de uso, pois é profusa na região, sendo conhecida como "árvore da vida".

Em relação ao conhecimento por gênero, os homens se destacam, pois conhecem o maior número de espécies. Os trabalhos de Santos et al. (2015) e Sousa et al. (2012) não apontaram diferenças significativas, mostrando que homens e mulheres atuam diretamente na pesca e que seu conhecimento é compartilhado. Já no trabalho de Nascimento (2014), o índice de Shannon apresentou diferenças significativas para o gênero. Este resultado está relacionado ao gênero masculino, em maior número, e também ao fato de haver pescadores que são carpinteiros e fazem o uso de várias espécies para a manufatura tanto de canoas como de apetrechos de pesca.

Em relação ao conhecimento sobre o nome das plantas usadas na atividade pesqueira e dos peixes é do entendimento dos jovens, adultos e idosos, homens e mulheres, havendo menos reconhecimento sobre plantas entre os jovens. Tais resultados foram semelhantes aos de Merétika et al. (2010), que relataram que nas comunidades pesqueiras do Sul do Brasil os jovens apresentaram menor conhecimento em relação aos idosos. Já no trabalho de Nascimento (2014), os idosos apresentaram menor conhecimento, quando comparados aos jovens e adultos. Os adultos mostraram deter maior conhecimento em relação aos jovens e idosos. Já a diversidade e a riqueza de espécies citadas por gênero e faixa etária recebem influências diretamente da pesca e um maior contato com a natureza.

\section{CONCLUSÃO}

Foram registradas 64 espécies, pertencentes a 54 gêneros e 30 famílias, sendo 56 espécies utilizadas pelos próprios peixes (42 como alimentícias, nove como berçário, oito como abrigo para desova e cinco como refúgio). As espécies que tiveram maior Valor de Uso foram Hymenachne amplexicaulis (capim 1), Megathyrsus maximus (capim 2) e Urochloa mutica (capim 3), apresentando mesmos valores $\left(\mathrm{VU}_{\mathrm{g}}=2,00 ; \mathrm{VU}_{\mathrm{a}}=1,60 \mathrm{e} \mathrm{VU}_{\mathrm{p}}=0,40\right)$.

O conhecimento e uso de plantas pelos pescadores da colônia Z-9 está relacionado ao convívio diário com o ambiente e os recursos pesqueiros, pois de acordo com suas necessidades, eles fazem o uso de espécies vegetais que lhes são úteis. Esses pescadores valorizam e transmitem o conhecimento botânico local, principalmente quanto à utilização na atividade pesqueira.

Os resultados sobre a diversidade e riqueza demonstram que o conhecimento que os informantes possuem em relação ao uso de espécies na atividade pesqueira é importante para a comunidade e como tal deve ser passado para as gerações futuras. Esse conhecimento tradicional proporciona práticas de conservação de espécies da região, que necessitam ser repassadas de uma geração a outra e para comunidade científica.

\section{AGRADECIMENTOS}

À Fundação de Amparo à Pesquisa no Piauí - FAPEPI/CNPq e à Coordenação de Aperfeiçoamento de Pessoal de Nível Superior - CAPES, pela concessão das bolsas. Aos pescadores artesanais cadastrados na colônia Z-9 do município de Castelo do Piauí, pela paciência e disponibilidade em repassar o conhecimento.

\section{REFERÊNCIAS}

ALBUQUERQUE, U.P.; ANDRADE, L.H.C. Uso de recursos vegetais da caatinga: o caso do agreste do estado de Pernambuco (Nordeste do Brasil). Interciência, Caracas, v. 27, n. 27, p. 336-346. 2002.

ALBUQUERQUE, U.P. Introdução à etnobotânica. 2. ed. Rio de Janeiro: Interciência, 2005.

ALBUQUERQUE, B.W. Frugivoria e ictiocoria em uma área de várzea na Amazônia Central Brasileira. 2015. 82 f. Dissertação (Mestrado em Ciências Biológicas) - Instituto Nacional de Pesquisas da Amazônia, Manaus, 2015.

ALMEIDA, M.Z. Plantasmedicinais. 3. ed. Salvador: EDUFBA, 2011.

ALMEIDA, A.F.; JARDIM, M.A.G. A utilização das espécies arbóreas da floresta de várzea da Ilha de Sororoca, Ananindeua, Pará, Brasil por moradores locais. Revista Brasileira de Ciências Ambientais,Belém, v. 23, n. 1, p. 48-54, 2012. 
AMORIM, A.N. Etnobiologia da comunidade de pescadores artesanais urbanos do bairro Poti Velho, Teresina/PI, Brasil. 2010. 124 f. Dissertação (Mestrado em Ciências Ambientais) - Universidade Federal do Piauí, Teresina, 2010.

ANDRADE, I.L.M.M.; LUCENA, E.A.R.M.; CHIAPETTI, J.; PEREIRA, R.C.A.; MIELKEM. S. Espécies arbóreas utilizadas por pescadores para a construção de jangadas, Área de Proteção Ambiental Costa de ItacaréSerra Grande, Bahia, Brasil. Revista Rodriguésia,Ilhéus,v. 67, n. 1, p. 45-53, 2016.

ANDRADE, I.M.; SILVA, M.F.S.; COSTA, M.C.A.; MAYO, S.J. Guia de campo macrófitas do Delta do Parnaíba. Parnaíba: EDUFPI, 2014.

APG IV. An update of the Angiosperm Phylogeny Group classification for the orders and families of flowering plants. Botanical Journal of the Linnean Society, p. 181:1-20, 2016.

APOLINÁRIO, F. Introdução à análise quantitativa de dados. In: APOLINÁRIO, F. (ed). Metodologia científica: filosofia e prática da pesquisa. São Paulo: Thomson Leaming, 2006. p. 145-168.

AZEVEDO, B.R.L. A importância socioambiental da bacia hidrográfica do rio Poty na formação da identidade cultural Piauiense. Castelo do Piauí. Carta Cepro, Teresina, v. 24, p. 1-7, 2007. Disponível em: <http://www.cepro.pi.gov.br/download/200806/CEPRO04_e7ff5947dc.pdf>. Acesso em: 06 de nov. 2018.

BALDUÍNO JÚNIOR, A.L.; BALDUINO, T.Y.; FRIEDERICHS, G.; CUNHA, A.B.; BRAND, M.A. Energetic potential of bamboo culms for industrial and domestic use in Southern Brazil. Revista Ciências Rural,Santa Maria, v. 46, n. 11, p. 1963-1968, 2016.

BARBOSA, A.R. Os humanos e os répteis da mata: uma abordagem etnoecológica de São José da Mata Paraíba. 2007. 144 f. Dissertação (Mestrado em desenvolvimento e Meio Ambiente) - Universidade Federal da Paraíba, João Pessoa, 2007.

BAPTISTA, M.M.; RAMOS, M.A.; ALBUQUERQUE, U.P.; COELHO-DE-SOUZA, G.; RITTER, M.R. Traditional botanical knowledge of artisanal fishers in southern Brazil. Journal of Ethnobiology and Ethnomedicine, v. 9, n. 54, p. 1-16, 2013.

BEGOSSI, A. Ecologia de pescadores da Mata Atlântica e da Amazônia.São Paulo: HUCITEC; NEPAM/UNICAMP, 2004.

BEGOSSI, A.; OLIVEIRA, E.C.; NAKANO, H. Ecologia de pescadores artesanais da Baía de Ilha

Grande.Rio de Janeiro: IBIO/Ministério da Justiça, 2009.

BERNARD, H.R. Research in cultural anthropology. Newbury Park: Sage, 1988.

BRASIL. Ministério da Integração Nacional. Nova delimitação do semiárido brasileiro. Brasília, 2007.

BRASIL. Ministério de Minas e Energia. Departamento Nacional de Produção Mineral.Projeto RADAM Levantamento dos recursos naturais, v. 2, folha SB. 23 / 24 - Teresina / Jaguaribe; geologia, geomorfologia, solos, vegetação e uso potencial da terra. Rio de Janeiro, 1973.

CAMARGO, M.T.L.A. Contribuição etnofarmacobotânica ao estudo de Petiveria alliacea L. - Phytolacaceae - ("amansa-senhor") e a atividade hipoglicemiante relacionada a transtornos mentais. Dominguezia, São Paulo, v. 23, n. 1, p. 21-27, 2007.

CARNEIRO, D.B.; BARBOZA, M.S.L.; MENEZES, M.P. Plantas nativas úteis na vila de pescadores da Reserva Extrativista Marinha Caeté-Tapiraçu, Pará, Brasil. Acta Botanica Brasilica, Belém, v. 24, n. 4, p, 1027 1033,2010

COLWELL, R.; CODDINGTON, J.A. Estimating terrestrial biodiversity through extrapolation. Philos. Trans. R. Soc. London B series, London, v. 345, p. 101-118,1994.

COLWELL, R.K. User's guide to EstimateS5 statistical. Estimation of species richness and shared species from samples. Version 7.0.0.Copyright 1994-2004. Disponível em: <http://viceroy.eeb.uconn.edu/estimates/>. Acesso em: 13 de set. 2019.

DIEGUES, A.C.; ARRUDA, R.S.V. Os saberes tradicionais e a biodiversidade no Brasil. In: DIEGUES, A.C. (Org.). Biodiversidade e comunidades tradicionais no Brasil.Brasília: Ministério do Meio Ambiente; São Paulo: USP, 2000.

DOMINGUEZ, D.R.; HEREDIA, L.B.; MARTÍNEZ, E.C.; LORES, R.I. Efecto del extracto hipoglicemiante de Petiveria alliacea L. sobre el consumo de glucosa por los eritrócitos.Revista Cubana de Investigaciones Biomedicas, La Habana, v. 21, n. 3, p. 161-166, 2002.

FLORA DO BRASIL 2020 em construção. Jardim Botânico do Rio de Janeiro. Disponível em <http://floradobrasil.jbrj.gov.br/>. Acesso em: 10 de jul. 2018.

FONSECA-KRUEL, V.S.; PEIXOTO, A.L. Etnobotânica na Reserva Extrativista Marinha de Arraial do Cabo, RJ, Brasil. Acta Botanica Brasílica,Rio de Janeiro, v. 18, n. 1, p. 177-190, 2004.

GANDOLFO, E.S.; HANAZAKI, N. Etnobotânica e urbanização: conhecimento e utilização de plantas de restinga pela comunidade nativa do distrito do Campeche (Florianópolis, SC). Acta Botanica Brasilica, Florianópolis, v. 25, n. 1, p. 168-177, 2011.

GENEROSO, A.L.; SANTOS, J.O.; CARVALHO, V.S.; SACOMAN, N.N.; RODRIGUES, R.S. Proposal for qualitative and quantitative descriptors to characterise bamboo germplasm. Revista Ciência Agronômica,Fortaleza, v. 47, n. 1, p. 47-55, 2016. 
GOMES, P.B. Avaliação dos efeitos centrais e antinociceptivos das frações isoladas da raiz de Petiveria alliacea L. (tipí) em camundongos. 2006. 174 f. Dissertação (Mestrado em Farmacologia) - Universidade Federal do Ceará, Fortaleza, 2006.

GOMES, J.M.A.; NASCIMENTO, W.L. Visão sistêmica da cadeia produtiva da carnaúba. In: GOMES, J.M.A.; SANTOS, $\quad$ K.B.; SILVA,

(Orgs). Cadeia produtiva da cera de carnaúba: diagnóstico e cenários. Teresina: EDUFPI, 2006.

GOTELLI, N.J.; ENTSMINGER, G.L. EcoSim: null models software for ecology. Version 7.0. Acquired Intelligence Inc. \& Kesey-Bear. 2001.

HANAZAKI, N. Etnobotânica. In: HANAZAKI, N. (Org.)Ecologia de pescadores da Mata Atlântica e da Amazônia. São Paulo: HUCITEC, 2004. p. 37-57.

HEGEL, C.G.Z.; MELO, E.F.R.Q. Macrófitas aquáticas como bioindicadoras da qualidade da água dos Arroios da RPPN Maragato. Revista em Agronomia e Meio Ambiente, Maringá,v.9, n. 3, p. 673-693, 2016.

IBGE. Instituto Brasileiro de Geografia e Estatística. Censo populacional. 2010. Disponível em: $<$ http://cidades.ibge.gov.br/xtras/temas.php?lang=\&codmun=220260\&idtema=16\&search=piaui|castelo-dopiaui|sintese-das-informacoes>. Acesso em: 23 jun. 2016.

IBGE - Instituto Brasileiro de Geografia e Estatística,Castelo do Piauí, Piauí, Brasil. v.4, n.3, p. 28.2017. Disponível em: <https://cidades.ibge.gov.br/brasil/pi/castelo-do-piaui/panorama>. Acesso em: ago. 2019.

KREBS, C.J. Ecological methodology. New York: Harper \& Row Publishers, 1989.

LOPES, L.C.M.; LOBÃO, A.T. Etnobotânica em uma comunidade de pescadores artesanais no litoral norte do Espírito Santo, Brasil. Boletim do Museu de Biologia Mello Leitão,Santa Teresa, (N. série), v. 32, p. 29-52, 2013.

LUCENA, R.F.P.; MEDEIROS, P.M.; ARAÚJO, E.L.; ALVEES, A.G.C.; ALBUQUERQUER, U.P. The ecological appearance hypothesis and the importance of useful plants in rural communities from Northeastern Brazil: an assessment based on use value. Journal of Environmental Management, v. 96, n. 1, p. 106-115, 2012.

MACEDO, R.M.; SOUZA, C.S.; MEDEIROS, L.C.; COSTA, D.F.S.; ROCHA, R.M. Macrófitas aquáticas como indicadoras do status de conservação dos reservatórios do semiárido do Brasil - estudo de caso no açude Itans (Caicós-RN). Revista de Biologia e Ciência da Terra,Campina Grande, v. 12, n. 1, p. 49-56, 2012.

MAGURRAN, A. Ecological diversity and its measurement. London: Croom-Helm, 1988.

MEDEIROS, M.F.T.; ALBUQUERQUE, U.P. Dicionário brasileiro de etnobiologia e etnoecologia. Recife: NUPEEA, 2012.

MELO, R.A.; DEUS, F.J.A. “As várias facetas de uma História”. Castelo do Piauí: Halley, 2008.

MERÉTIKA, A.H.C.; PERONI, N.; HANAZAKI, N. Local knowledge of medicinal plants in three artisanal fishing communities (Itapoá, Soutervan Brazil), according to gender, age, and urbanization. Acta Botanica Brasilica, Florianópolis, v. 24, n. 2, p. 386-394, 2010.

MORAIS, F.F.; SILVA, C.J. Conhecimento ecológico tradicional sobre fruteiras para pesca na comunidade de Estirão Comprido, Barão de Melgaço - Pantanal Mato-grossense. Biota Neotropical, São Paulo, v. 10, n. 3, p. 197-203, 2010.

MORI, A.S.; SILVA, L.A.M.; LISBOA, G.; CORADIN, L. Manual de manejo do herbário fanerogâmico. 2. ed. Ilhéus: CEPLAC: CEPLEC, 1989

MUNIZ, C.C.; ALENCAR, S.S.; ANDRADE, M.L.F.; OLIVEIRA JUNIOR, E.S.; FURLAN, A.O.; CARNIELlO, M.A. Dispersão de sementes por Piaractusmesopotamicus Holmberg, 1887 (Osteichthyes, Characidae) na Estação Ecológica de Taiamã, Pantanal Norte, MT. Ambiência - Revista do Setor de Ciências Agrárias e Ambientais, Guarapuava, v.10, n.3, p. 663-676, 2014.

NASCIMENTO, M.G.P. Etnobotânica e Etnozoologia em comunidades pesqueiras de Parnaíba e Cajueiro da Praia, Piauí, Brasil. 2014. 144 f. Dissertação (Mestrado em Desenvolvimento e Meio Ambiente) Universidade Federal do Piauí, Teresina, 2014.

NISHIDA, A.K.; NORDI, N.; ALVES, R.R.N. Embarcações utilizadas por pescadores estuarinos da Paraíba, Nordeste Brasil. Revista de Biologia e Farmácia, João Pessoa, v. 3, n. 1, p. 45-52, 2008.

OLIVEIRA, F.R. Avaliação antifúngica, farmacognóstica e toxicológica sazonal de Petiveria alliacea $\mathbf{L}$. (Phytolacaceae). 2012. 108 f. Dissertação (Mestrado em Ciências Farmacêuticas) - Universidade Federal do Pará, Belém, 2012.

PANTOJA, S.C.S.; SUL, N.A.S.; MIGUEL, N.N. Levantamento etnobotânico de Petiveriaalliacea L. (Phytolacaceae) comercializadas no mercadão de Madureira-RJ. Revista Eletrônica Novo Enfoque, Rio de Janeiro, v. 17, n. 17, p. 184-190, 2013.

PASA, M.C.; SOARES, J.J.; GUARIM NETO, G. Estudo etnobotânico na comunidade de Conceição-Açu (alto da bacia do rio Aricá Açu, MT, Brasil). Acta Botanica Brasilica, Florianópolis, v. 19, n. 2, p. 195-207, 2005.

PESSOA, C.R.M.; MEDEIROS, R.M.T.; RIET-CORREA, F. Importância econômica, epidemiologia e controle das intoxicações por plantas no Brasil. Pesquisa Veterinária Brasileira,Rio de Janeiro, v. 33, n. 6, p. 752-758, 2013.

RIBEIRO, L.G. G.; BRITO, N.B.V. Participação das comunidades tradicionais na lei de acesso aos recursos genéticos: diálogos com a Teoria Discursiva do Direito em Habermas. Revista Brasileira de Direito,Passo Fundo, v. 14 , n. 1 , p. $149-175,2018$ 
ROQUE, T.V. Conhecimento e uso de espécies arbóreas para construção e manutenção de canoas-deum-pau-só no litoral central de Santa Catarina. 2017. 110 f. Dissertação (Mestrado em Biologia de Fungos, Algas e Plantas) - Universidade Federal de Santa Catarina, Florianópolis, 2017.

ROSSATO, S. C.; LEITÃO FILHO, H. F.; BEGOSSI A. Ethnobotany of caiçaras of the Atlantic Forest Coast (Brazil). Economic Botany, Campinas, v.53, n. 4, p. 377-385, 1999.

SANTANA, G.M.; LELIS, R.C.C.; JAGUARIBE, E.F.; MORAIS, R.M.; PAES, J.B.; TRUGILHO, P.F. Development of activated carbon from bamboo (Bambusa vulgaris) for pesticide removal from aqueous solutions. Revista Cerne, Larvas, v.3, n. 1, p. 123-132, 2017.

SANTOS, F.A.; AQUINO, C.M.S. Características geoambientais de Castelo do Piauí e Juazeiro do Piauí, nordeste, Brasil. Geografia em Questão,Teresina,v. 8, n. 2, p. 27-42, 2015.

SANTOS, K.P.P.; SOARES, R.R.; BARROS, R.F.M. Atividade pesqueira e construção de embarcações na colônia de pescadores Z-18 do município de União/ PI. Holos, Natal, v. 31, n. 6, p. 90-106, 2015.

SANTOS, K. P. P. Etnozoologia e Etnoecologia na Comunidade de Pescadores Artesanais de Miguel Alves, PI/Brasil. 2017. 199 f. Tese (Doutorado em Desenvolvimento e Meio Ambiente) - Universidade Federal do Piauí, Teresina.

SILVA, V.G. O Antropólogo e sua magia. São Paulo: Edusp, 2000.

SILVA, S.S.L. Caracterização ecológica e estrutural de macrófitas em reservatórios no estado de Pernambuco. 2011. 107 f. Tese (Doutorado em Botânica) - Universidade Rural de Pernambuco, Recife, 2011.

SILVA, A.B. Conhecimento ecológico tradicional do manejo da ictiofauna na comunidade de pescadores artesanais de Amarante, Piauí, Brasil. 2018. 65 f. Dissertação (Mestrado em Desenvolvimento e Meio Ambiente) - Universidade Federal do Piauí, Teresina, 2018.

SOUSA, R.S.; HANAZAKI, N.; LOPES, J.B.; BARROS, R.F.M. Are gender and age important in understanding distribution of local botanical knowledge in fishing communities of the Parnaiba Delta? Ethnobotany Research \& Applications,Manoa, v. 10, p. 551-559, 2012.

THORNTHWAITE, C.W.; MATHER, J.R. Water balance. New Jersey: Drexel Institute of Technology, v. 8, n. $1,1955$.

VÁSQUEZ, S.P.F.; MENDONÇA, M.S.; NODA, S.N. Etnobotânica de plantas medicinais em comunidades ribeirinhas do município de Manacapuru, Amazonas, Brasil. Revista Acta Amazônica,Manaus, v. 44, n. 4, p. 457-472, 2014.

WIRYONO; JAPRIYANTO; ERNIWATIJ, E. The diversity of locally utilized plants and local botanical knowledge in Central Bengkulu District, Bengkulu Province, Indonesia. Biodiversitas, Bengkulu, v. 18, n. 4, p. 1589-1595, 2017.

W3trópicos. [Online Database]. Missouri Botanical Garden. MOBOT. 2013. Disponível em: <http://www.tropicos.org.>. Acesso em: 20 jul. 2016. 
Anexo 1: Lista das espécies de plantas utilizadas na atividade pesqueira pelos entrevistados do município de Castelo do Piauí - PI. Legenda:Cat. de uso = Categorias de uso: Al-

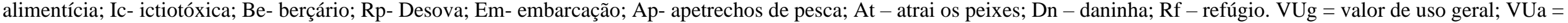
valor de uso atual; VUp = valor de uso potencial. Hábito: herb= herbácea; erv = erva; sub = subarbusto; arb = arbusto; arv = árvore; lia = liana; Habitat: ter = terrestre; aqu = aquática. Status $(S t)$ : e = exótica; $\mathrm{n}=$ nativa do Brasil. $\mathrm{N}^{\mathrm{o}}$ col.= número de coletor.

\begin{tabular}{|c|c|c|c|c|c|c|c|c|c|c|}
\hline Família/Nome científico & Nome vulgar & Cat. de uso & Parte utilizada & Status & Hábito & Habita & $\mathbf{V U g}$ & VUa & VUp & $\mathbf{N}^{0}$ col. \\
\hline \multicolumn{11}{|l|}{ ALISMATACEAE } \\
\hline Echinodorus lanceolatus Rataj & $\begin{array}{l}\text { capim-beira- } \\
\text { d'água }\end{array}$ & $\mathrm{Al}, \mathrm{Dn}$ & $\mathrm{Fl}$, fo & $\mathrm{N}$ & Erv & Aqu & 0.018 & 0.018 & - & 43 \\
\hline \multicolumn{11}{|l|}{ ANACARDIACEAE } \\
\hline Anacardium occidentale L. & caju & $\mathrm{Al}, \mathrm{At}$ & Fr & $\mathrm{N}$ & Arb & Ter & 0.018 & 0.018 & - & 14 \\
\hline $\begin{array}{l}\text { Spondias mombin L. } \\
\text { APOCYNACEAE }\end{array}$ & cajá & $\mathrm{Al}$ & $\mathrm{Fr}$ & $\mathrm{N}$ & Arb & Ter & 0.109 & 0.109 & - & 62 \\
\hline Aspidosperma multiflorum A.DC. & pereiro-branco & Ap & $\mathrm{Ca}$ & $\mathrm{N}$ & Arb & Ter & 0.255 & 0.255 & - & 25 \\
\hline Aspidosperma pyrifolium Mart. \& Zucc. & pereiro-preto & Ap & $\mathrm{Ca}$ & $\mathrm{N}$ & Arb & Ter & 0.255 & 0.255 & - & 59 \\
\hline $\begin{array}{l}\text { Aspidosperma subincanum Mart. } \\
\text { ARECACEAE }\end{array}$ & piquiá & Ap & $\mathrm{Ca}$ & $\mathrm{N}$ & Arb & Ter & 0.073 & 0.073 & - & 8 \\
\hline $\begin{array}{l}\text { Copernicia prunifera (Mill.) H.E.Moore } \\
\text { BIGNONIACEAE }\end{array}$ & \multicolumn{9}{|c|}{ BIGNONIACEAE } & 29 \\
\hline $\begin{array}{l}\text { Fridericiadispar (Bureau ex K.Schum.) } \\
\text { L.G.Lohmann }\end{array}$ & bugi & $\mathrm{Al}, \mathrm{Be}$ & $\mathrm{Fl}, \mathrm{Ca}, \mathrm{Fo}$ & $\mathrm{N}$ & Lia & Ter & 0.018 & 0.018 & - & 72 \\
\hline $\begin{array}{l}\text { Handroanthus impetiginosus(Mart. ex } \\
\text { DC.) Mattos }\end{array}$ & pau-d'arco-roxo & Ap, Em & $\mathrm{Ca}$ & $\mathrm{N}$ & Arb & Ter & 0.164 & 0.164 & - & 74 \\
\hline $\begin{array}{l}\text { Handroanthus serratifolius (Vahl) } \\
\text { S.Grose } \\
\text { BORAGINACEAE }\end{array}$ & $\begin{array}{l}\text { pau-d'arco- } \\
\text { amarelo }\end{array}$ & Ap, Em & $\mathrm{Ca}$ & $\mathrm{N}$ & Arb & Ter & 0.164 & 0.164 & - & 77 \\
\hline Cordia rufescens A.DC. & grão-de-galo & $\mathrm{Al}$ & $\mathrm{Fr}$ & $\mathrm{N}$ & Sub & Ter & 0.018 & 0.018 & - & 19 \\
\hline \multicolumn{11}{|l|}{ BROMELIACEAE } \\
\hline $\begin{array}{l}\text { Encholirium spectabile Mart. ex Schult. } \\
\text { \& Schult.f. } \\
\text { CARYOCARACEAE }\end{array}$ & macambira & $\mathrm{Al}, \mathrm{Ap}$ & $\mathrm{Fr}$ & $\mathrm{N}$ & Erv & Ter & 0.018 & 0.018 & - & 97 \\
\hline Caryocar coriaceum Wittm. & piqui & Em & $\mathrm{Ca}$ & $\mathrm{N}$ & Arb & Ter & 0.018 & 0.018 & - & 78 \\
\hline Caryocar sp. & $\begin{array}{l}\text { piquizeiro-do- } \\
\text { pará }\end{array}$ & Em & $\mathrm{Ca}$ & $\mathrm{N}$ & Arb & Ter & 0.164 & 0.164 & - & \\
\hline
\end{tabular}




\section{CERATOPHYLLACEAE}

Ceratophyllum demersum $\mathrm{L}$ CHRYSOBALANACEAE

Couepia uiti (Mart. \& Zucc.) Benth. ex Hook.f.

Licania rigida Benth.

COMBRETACEAE

Combretum laxum Jacq.

Combretum leprosum Mart.

CONVOLVULACEAE

Ipomoea asarifolia Roem. \& Schult.

\section{DILLENIACEAE}

Curatella americana $\mathrm{L}$.

\section{EUPHORBIACEAE}

Croton blanchetianus Baill.

Manihot esculenta Crantz

\section{FABACEAE}

Anadenanthera colubrina (Vell.) Brenan Anadenanthera macrocarpa (Benth.)

Brenan

Andira retusa (Poir.) A.DC.

Bauhinia rufa (Bong.) Steud.

Enterolobium maximum Ducke

Hymenaea martiana Hayne

Hymenaea stigonocarpa Mart. ex Hayne

Inga uruguensis Hook. \& Arn.

Inga uruguensis Hook. \& Arn.

Mimosa caesalpiniifolia Benth.

Mimosa verrucosa Benth.

Piptadenia moniliformis Benth

\section{golfo-d’água}

Al, Rf, Rp

$\mathrm{Fl}, \mathrm{Ca}, \mathrm{Fo}$

$\mathrm{Al}$

$\mathrm{Al}$

Fr

oiticica

jaramataia

Al, Ap, Be, Fl, Fr, Ca, Fo $\mathrm{Rp}$

mufumbo-preto

Al, Ap, Be

Fl, Fr, Ca, Fo

$\mathrm{Be}, \mathrm{Ic}$

$\mathrm{Ca}, \mathrm{Fo}$

Ic

$\mathrm{Ca}$

marmeleiro

mandioca

Ap

At

$\mathrm{Ca}$

angico-preto

angico-

verdadeiro

angelim

mororó

tamboril

bruto

jatobá

engarana

ingá

sabiá

jurema-de-

espinho

rama-de-bezerro
$\mathrm{Al} \quad \mathrm{Fl}, \mathrm{Fr}$

Al Fl, Fr

Em

Ap

Em

Al

Em

Al, Ap, Be

$\mathrm{Al}$

Ap

Al, Ap

Ap
$\mathrm{Fl}, \mathrm{Fr}$

$\mathrm{Ca}$

$\mathrm{Ca}$

$\mathrm{Ca}$

$\mathrm{Fl}, \mathrm{Fr}$

$\mathrm{Ca}$

Fl, Fr, Ca, Fo

$\mathrm{Fl}, \mathrm{Fr}, \mathrm{Ca}, \mathrm{Fo}$

$\mathrm{Ca}$

$\mathrm{Fl}, \mathrm{Fr}, \mathrm{Ca}$

$\mathrm{Ca}$
Aqu

0.018

0.018

$0.018 \quad 0.018$

$0.036 \quad 0.036$

0.291

0.018

$0.091 \quad 0.091$

$-$

Erv

Arb

Arb

Lia

Arb

Arb

Arb

Arb

Arb

Arb

Arb

Arb

Arb

Arb

Arb

Arb $\begin{array}{lll}0.036 & 0.018 & 0.018\end{array}$

Ter

0.018

$-$

0.018

Ter

0.164

0.164

$\overline{0.018}$

30

$\begin{array}{llll}0.018 & - & 0.018 & 87\end{array}$

Ter

$\begin{array}{llll}0.018 & 0.018 \quad-\quad 100\end{array}$

$\begin{array}{llll}0.018 & 0.018 \quad-\quad 27\end{array}$

$0.236 \quad 0.236$

$0.073 \quad 0.073$

$0.127 \quad 0.127$

$0.018 \quad 0.018$

$0.127 \quad 0.127$

$0.145 \quad 0.145$

$0.091 \quad 0.091$

$0.055 \quad 0.055$

$0.018 \quad 0.018$

$0.018 \quad 0.018$ 


\section{LECYTHIDACEAE}

\section{Lecythis $\mathrm{sp}$}

MALPIGHIACEAE

Byrsonima crassifolia (L.) Kunth

Malpighia glabra L.

MELASTOMATACEAE

Mouriri sp.

\section{MYRTACEAE}

Eugenia L.

Psidium cattleianum Sabine

\section{NYMPHAEACEAE}

Nymphaea rudgeana G.Mey.

\section{ONAGRACEAE}

Ludwigia helminthorrhiza (Mart.)

H.Hara

\section{PASSIFLORACEAE}

Passiflora cincinnata Mast.

\section{PHYTOLACCACEAE}

Petiveria alliacea $\mathrm{L}$.

\section{PLANTAGINACEAE}

\section{POACEAE}

Bambusa sp.

Cyperus digitatus Roxb.

Hymenachne amplexicaulis (Rudge)

Nees

Megathyrsus maximus (Jacq.) B.K.Simon \& S.W.L.Jacobs

Oryza sativa $\mathrm{L}$.

\begin{tabular}{|c|c|c|}
\hline sapucaia & Em & $\mathrm{Ca}$ \\
\hline murici & $\mathrm{Al}$ & $\mathrm{Fr}$ \\
\hline acerola & $\mathrm{Al}, \mathrm{At}$ & $\mathrm{Fr}$ \\
\hline criolí & $\mathrm{Al}$ & $\mathrm{Fr}$ \\
\hline araçá-de-boi & $\mathrm{Al}$ & $\mathrm{Fr}$ \\
\hline araça & $\mathrm{Al}$ & $\mathrm{Fr}$ \\
\hline peixe-come & $\mathrm{Al}$ & $\mathrm{Fr}$ \\
\hline aguapé & $\begin{array}{l}\mathrm{Al}, \mathrm{Be}, \mathrm{Dn}, \\
\mathrm{Rp}\end{array}$ & Fo, Fl \\
\hline aguapé & $\begin{array}{l}\mathrm{Al}, \mathrm{Be}, \mathrm{Dn}, \\
\mathrm{Rp}\end{array}$ & $\mathrm{Fo}, \mathrm{Fl}$ \\
\hline $\begin{array}{l}\text { maracujá-do- } \\
\text { mato }\end{array}$ & $\mathrm{Al}$ & $\mathrm{Fl}, \mathrm{Fr}$ \\
\hline tipi & Ic & $\mathrm{Ra}$ \\
\hline rabo-de-raposa 1 & $\mathrm{Al}$ & $\mathrm{Fr}$ \\
\hline bambu & Ap & $\mathrm{Ca}$ \\
\hline capim-tiririca & $\mathrm{Al}, \mathrm{Dn}$ & Fo, Fl, Se \\
\hline capim 1 & $\begin{array}{l}\mathrm{Al}, \mathrm{Be}, \mathrm{Dn}, \\
\mathrm{Rf}, \mathrm{Rp}\end{array}$ & $\mathrm{Fo}, \mathrm{Fl}, \mathrm{Se}$ \\
\hline capim 2 & $\begin{array}{l}\mathrm{Al}, \mathrm{Be}, \mathrm{Dn}, \\
\mathrm{Rf}, \mathrm{Rp}\end{array}$ & Fo, Fl, Se \\
\hline arroz & $\mathrm{Al}, \mathrm{At}$ & $\mathrm{Se}$ \\
\hline
\end{tabular}

\begin{tabular}{|c|c|c|c|c|c|}
\hline $\mathrm{N}$ & Arb & Ter & 0.018 & 0.018 & - \\
\hline $\mathrm{N}$ & Arb & Ter & 0.018 & 0.018 & - \\
\hline \multirow[t]{2}{*}{$\mathrm{E}$} & Arb & Ter & 0.036 & 0.018 & 0.018 \\
\hline & Arb & Ter & 0.418 & 0.418 & - \\
\hline $\mathrm{N}$ & Arb & Ter & 0.018 & 0.018 & - \\
\hline \multirow[t]{2}{*}{$\mathrm{N}$} & Arb & Ter & 0.018 & 0.018 & - \\
\hline & Arb & Ter & 0.018 & 0.018 & - \\
\hline $\mathrm{N}$ & Erv & $\mathrm{Aqu}$ & 0.091 & 0.073 & 0.018 \\
\hline $\mathrm{N}$ & Erv & $\mathrm{Aqu}$ & 0.091 & 0.073 & 0.018 \\
\hline $\mathrm{N}$ & Lia & Ter & 0.018 & 0.018 & - \\
\hline \multirow[t]{2}{*}{$\mathrm{E}$} & Arb & Ter & 0.018 & - & 0.018 \\
\hline & Arb & Ter & 0.018 & 0.018 & - \\
\hline $\mathrm{E}$ & Arb & Ter & 0.345 & 0.345 & - \\
\hline $\mathrm{N}$ & Erv & Ter & 0.018 & 0.018 & - \\
\hline $\mathrm{N}$ & Erv & Ter & 2.000 & 1.600 & 0.400 \\
\hline $\mathrm{N}$ & Ver & Ter & 2.000 & 1.600 & 0.400 \\
\hline $\mathrm{E}$ & Arb & Ter & 0.018 & - & 0.018 \\
\hline
\end{tabular}




\begin{tabular}{|c|c|c|c|c|c|c|c|c|c|c|}
\hline Urochloa mutica (Forssk.) T.Q.Nguyen & capim 3 & $\begin{array}{l}\text { Al, Be, Dn, } \\
\text { Rf, Rp }\end{array}$ & $\mathrm{Fo}, \mathrm{Fl}, \mathrm{Se}$ & $\mathrm{E}$ & Ver & Ter & 2.000 & 1.600 & 0.400 & 53 \\
\hline Zea mays $\mathrm{L}$ & milho & $\mathrm{Al}$ & Fr & $\mathrm{N}$ & Sub & Ter & 0.018 & 0.018 & - & 6 \\
\hline \multicolumn{11}{|l|}{ RHAMNACEAE } \\
\hline Ziziphus joazeiro Mart. & juá & $\mathrm{Al}$ & Fr & $\mathrm{N}$ & Arb & Ter & 0.018 & 0.018 & - & 58 \\
\hline \multicolumn{11}{|l|}{ RUBIACEAE } \\
\hline $\begin{array}{l}\text { Cordiera myrciifolia (K.Schum.) } \\
\text { C.H.Perss. \& Delprete }\end{array}$ & maria-preta & $\mathrm{Al}$ & Fr & $\mathrm{N}$ & Arb & Ter & 0.018 & 0.018 & - & 104 \\
\hline Genipa americana $\mathrm{L}$. & jenipapo & $\mathrm{Al}$ & Fr & $\mathrm{N}$ & Arb & Ter & 0.018 & 0.018 & - & 102 \\
\hline \multicolumn{11}{|l|}{ SALVINACEAE } \\
\hline Salvinia auriculata Aubl. & igarapé- novo & $\begin{array}{l}\mathrm{Al}, \mathrm{Be}, \mathrm{Dn}, \\
\mathrm{Rf}, \mathrm{Rp}\end{array}$ & $\mathrm{Fl}, \mathrm{Fo}$ & $\mathrm{N}$ & Erv & Aqu & 0.091 & 0.073 & 0.018 & 44 \\
\hline \multicolumn{11}{|l|}{ SAPINDACEAE } \\
\hline Magonia pubescens A.St.-Hil. & tingui & Ic, Dn & $\mathrm{Ra}$ & $\mathrm{N}$ & Arb & Ter & 0.182 & 0.018 & 0.164 & 13 \\
\hline Paullinia pinnata $\mathrm{L}$. & mata-fome & $\mathrm{Al}$ & Fr e Fl & $\mathrm{N}$ & Lia & Ter & 0.018 & 0.018 & - & 94 \\
\hline Sapindus saponaria $\mathrm{L}$. & sabonete & $\mathrm{Al}$ & $\mathrm{Fr}$ & $\mathrm{N}$ & Arb & Ter & 0.018 & 0.018 & - & 55 \\
\hline \multicolumn{11}{|l|}{ SAPOTACEAE } \\
\hline Pouteriaramiflora(Mart.) Radlk. & pitomba de leite & $\mathrm{Al}$ & Fr & $\mathrm{N}$ & Arb & Ter & 0.018 & 0.018 & - & 105 \\
\hline \multicolumn{11}{|l|}{ SIMAROUBACEAE } \\
\hline Simaba cedron Planch. & rabo-de-raposa 2 & $\mathrm{Al}$ & Fr & $\mathrm{N}$ & Arb & Ter & 0.018 & 0.018 & - & 103 \\
\hline Simarouba versicolor A.St.-Hil. & Praiba & Ic & $\mathrm{Ra}$ & $\mathrm{N}$ & Arb & Ter & 0.055 & - & 0.055 & 75 \\
\hline
\end{tabular}

